\title{
TEMPORAL HORIZONS OF JUSTICE
}

$\mathrm{W}$ are mortal creatures. Perhaps we might live human lives without seriously confronting death. But while we are alive, we cannot avoid making sense of life's meaning by locating ourselves in time. Some will tell elaborate narratives about their past, present, and future. Others will look on these hyperorganized accounts with disdain or despair, and content themselves with more fragmentary stories. But without any sense of past, present, future, we are nothing.

So much is obvious. But it is less obvious how our ongoing effort at temporal self-location shapes thinking about justice. I elaborate three temporal horizons that we are continually using to make sense of our lives. Each horizon frames time in a different way, irreducible to the others. Each is irreplaceable. We must make our peace with all three, despite their potential conflicts with the others. As we explore two of these horizons, we find ourselves on a path that leads to new insights into an old idea-that there is a basic difference between corrective and distributive justice. Exploring a third will lead us into less familiar, but equally fundamental, terrain: I shall call it the sphere of relational justice.

This tripartite view permits a fresh encounter with more familiar monistic and dualistic perspectives. Monists hope to work out a single idea of justice that will fit all kinds of disputes. Some have been notoriously simple-minded-as in Benthamite utility maximization or Posnerian wealth maximization. But there is nothing in monism that requires brutal simplicity. You can be as complicated as you like in developing your idea of justice-so long as you think that the right idea, once elaborated, should apply to all possible cases.

Dualists have no such expectation. They follow Aristotle and assert that justice comes in two varieties-corrective and distributive. John Rawls, for example, does not suppose that his famous difference principle should regulate our ideas of corrective justice. Robert Nozick $^{1}$ and many other conservatives have attacked Rawls on monistic grounds: If Rawlsian justice cannot be used to inform microdiscussions of particular cases, why should we trust it to regulate the basic structure of society?

An analogous dispute has been provoked by the rise of the lawand-economics movement over the last generation. This time, tradi-

${ }^{1}$ See Anarchy, State and Utopia (New York: Basic, 1974), pp. 204-13.

0022-362X/97/9406/299-317

(C) 1997 The Journal of Philosophy, Inc. 
tionalists tend to be dualists. On their view, lawyer-economists make a category mistake when they test the rules of contract, tort, and crime by one or another conception of efficiency. Instead, legal developments should be guided by the very different commands of corrective justice. ${ }^{2}$ For lawyer-economists, this move merely mystifies potential irrationalities and inefficiencies in the name of an obscure label, signifying nothing.

Disagreements between monists and dualists do not break down on political lines: conservatives are not necessarily dualists, liberals are not necessarily monists, or the other way round. Despite the antiquity and intensity of the dispute, we do not seem to have much of an idea about what is dividing the two sides. Monists and dualists are generally content to accuse one another of moral blindness-for monists, dualists are perverse obscurantists; for dualists, monists are barbaric simplifiers-without trying to understand why their apparently intelligent opponents fail to appreciate the error of their ways.

I shall be suggesting that both sides tend to give priorities to different time frames, and that both are right in supposing their opponents miss something important. Once we understand the dispute in this way, we shall no longer be tempted to suppress the insights of either side. It may prove possible to incorporate the insights of both schools into a more complex, trinitarian, concept of justice.

\section{CLOCK WATCHING}

Let me begin the modern way-by inviting you to look at your watch. Unlike the denizens of previous civilizations, it is second nature for us to walk around with a device that constantly tells us that time is like a line in space. Just as we can subdivide a line into homogeneous and infinitely divisible units, we can subdivide the time line by glancing at our watch. The only difference is that once we have passed a point on the time line, there is no returning.

Now, you do not have to be Albert Einstein to know that this linear analogy between space and time has proved unsatisfactory for scientific purposes. But I am not doing science here, or even the philosophy of science. My aim is to elaborate the temporal frameworks used by ordinary men and women to make sense of the meaning of their lives. These frameworks provide the context within which these same ordinary people seek to realize justice in the law of a democratic society.

${ }^{2}$ See, for example, George Fletcher, "Fairness and Utility in Tort Theory," Harvard Law Review, LXXXV (January 1972): 537-73; Ernest Weinrib, "Legal Formalism: On the Immanent Rationality of Law," Yale Law Journal, XCVII (May 1988): 9491016. 
From this viewpoint, the most important event of the twentieth century is not the triumph of Einstein, but the triumph of the wristwatch. While modern men and women differ vastly in other respects, all are trained to measure out their lives in clock beats. It is one thing to arrive habitually late for appointments; quite another to refuse to wear a wristwatch or look at a clock. Such a blank stare would mark a person off as an alien presence: either she is a recent arrival from Mars or a philosophy student momentarily in the grip of John McTaggart's proof of time's unreality.

This essay does not try to vindicate clock time against its radical critics. I shall be struggling against a more common reaction. We sometimes take clock time so seriously that, despite Einstein, we suppose that it describes the nature of ultimate reality, that it is the only "real" way we can talk about time and its passage. But if we think about how we actually live out our lives, it is surprisingly easy to loosen the grip of the wristwatch upon our time consciousness.

I do not deny that the time line provides modern men and women with an irreplaceable temporal framework. But it is not the only form in which time, and its passage, appears to us. In contrast to clock time, these other forms are neither infinitely divisible nor homogeneous. They are nonetheless very real.

\section{THE LIVED PRESENT}

We live in the present. Each time we awake, we are thrown into the world of the now, and we cannot escape the task of interpreting the meaning of what is going on. Right now, for example, I am writing this line, and you are now reading it.

The present, for us, is not an infinitely small point on a line, but a structured experience. The key is recognition of change-whenever I notice that something significant has happened, this recognition serves to reframe my understanding of what is going on right now.

Insignificant things do not matter. As you read this essay, the significant event is the word or phrase. You are not aware, nor should you be, of the clock time it takes to decode a single letter-unless, of course, you reinterpret the nature of your structured activity and experience this essay as a challenge to identify the letters of the alphabet. Even then, your lived present would not be infinitely divisible into clock time. As you happily called out the letters on the page, you would be failing to notice many changes occurring at a different rate. While a clock can measure the passage of a nano-second, this is too short for a human being to focus his attention and begin to make sense of the world in which he finds himself. 
So much for the lived present. A lot more can be said, ${ }^{3}$ but despite my brevity, I am sure that you know what I am talking about. Rather than explore the now at greater length, I want to describe three ways of making sense of the now by placing it into longer, but differently constructed, temporal horizons. As I display each horizon, I shall also suggest how it shapes our sense of justice in a different way.

III. LIVED EXPERIENCE

First (and foremost?), each of us frames the now by placing it against a background of lived experience. I am now reading an essay, or playing baseball, or working on an assembly line. Each of these experiences lasts longer than the now, but none lasts too long. For one thing, their duration is limited by an internal understanding of the particular experience: if, say, I am playing baseball, and I strike out to end the ninth inning, I have come to the end of the game. While I may remember my experience a minute later as I brood about my strikeout in the shower room, I am perfectly aware that I am now "taking a shower" - a different experience altogether.

In contrast, when I went up to bat in the ninth inning, I was still experiencing the same game I started in the first inning-even if the game began several hours ago. It is the internal structure of my ongoing activity, not clock time, that marks off one lived experience from the next.

While an activity's internal structure is important, human physiology also imposes constraints. 'Let's stop for lunch' generally serves to call a halt to whatever we were doing; when we pick up afterward, we experience ourselves as starting up anew-the lunch break typically interrupts the sense of continuous engagement in a developing structure of experience which is the hallmark of the first temporal horizon. It is possible, of course, to defer termination of a lived experience by refusing to eat or sleep and by focusing attention on it alone. But soon enough, it will prove impossible to evade the demands of the body; and when you awake from your fitful slumbers, you will be opening your eyes to new lived experience(s) - even if they occur in the very same sequence as yesterday's.

The familiar rhythms of lived experience shape a first understanding of the demand for justice. Begin with the simple point that each lived experience is understood as having a structure: a set of expectations about the way in which one now can appropriately evolve into the next. If I am reading a philosophical essay, I may

${ }^{s}$ My own thinking begins with the brilliant, if obscure, work of Edmund Husserl's On the Phenomenology of Internal Time Consciousness, John Barnett Brough, trans. (Dordrecht: Kluwer, 1991). 
plan to read one paragraph and then the next; if I am working at McDonald's Restaurant, my expectations have a more complicated structure, allowing for more-but not infinitely more-appropriate ways in which my actions at one time may evolve into my experience at the next.

This elementary point suffices to formulate a basic question of justice: since each of your lived experiences has a structure, each is vulnerable to disruption. For example, you are now trying to make sense of this essay. Suppose Shmoe disrupts this effort by blasting a loud horn within earshot: What in the world, you say, is going on? Who does Shmoe think he is? What gives him the right to blast away at the structure of my lived experience?

Notice how naturally this temporal horizon frames the characteristic concerns of corrective justice. Your questions cannot be assimilated into some general complaint about the way society as a whole is organized. The problem is not society but Shmoe, and his disruptive behavior.

Not that Shmoe will find it impossible to answer your questions about his actions. Most fundamentally, he may deny his responsibility for the disintegration of your structured expectations-pointing, for example, to the fact that a third person, Blow, forced him to play his horn at gun point. In this case, you have misdirected your complaint, and had better redirect it appropriately.

Worse yet, you may find that there is nobody responsible for the disruption. After all, the world has not been organized to guarantee the integrity of all your lived experiences-you may simply be the victim of misfortune. Even if you can locate the responsible actor(s), he may plausibly respond with an excuse or justification for his conduct-perhaps he did not notice you sitting quietly in the shady corner, or perhaps he was sounding a fire alarm, or....

My aim is not to appraise any of these responses-this is the task of a full-blown theory of corrective justice. I am concerned with the temporal horizons that make these theories significant. From this point of view, the most important-and appealing-thing about corrective justice is its principled refusal to abandon the frame of lived experience, its insistence on understanding the problem of justice in terms that make sense within the narrow temporalities in which life is actually experienced from day to day. Rather than seek relief from disruption in the reorganization of social processes whose character only displays itself over larger tracts of time, corrective justice focuses remorselessly on the par- 
ticular people who disrupt particular experiences at particular moments. ${ }^{4}$

Even within these confines, it focuses narrowly on those particularities which illuminate individual responsibility for the disruption. It generally casts a blind eye on whether Shmoe is rich or poor, but closely scrutinizes whether he noticed your presence in the room before putting the trumpet to his lips. It is the latter, not the former, that singles Shmoe out from your perspective of lived experience. To make this point, I shall say that the accent of justice within this time frame is on the responsibility of persons, with different approaches to corrective justice elaborating different variations on this theme.

For all the trendy talk about the "socially contingent" nature of human reality, it is hard to imagine how homo sapiens might dispense with the habits of experiencing life in chunklets of an hour or two, and of responding with outrage when others disrupt their patterned expectations about the way these chunklets "normally" evolve. It is this sense of outraged expectation which fuels the demand for corrective justice.

Indeed, corrective justice would be the only meaningful kind of justice if the structure of lived experience provided us with the only way we could ever understand the meaning of life. But it does not. IV. RELATIONSHIPS

Particular experiences can be interesting, boring, or profoundly revealing. But they gain new meanings when we organize them into patterns that unfold over longer periods of time-patterns that I shall call relationships.

Imagine, for example, that I teach a particularly bad class-disorganized and obtuse, I lose touch with the concerns of my students. Retreating to my office in disarray, I place my recent pedagogic disaster into a larger pattern of activity: After all is said and done, am I a third-rate teacher? To answer, it is not enough to fixate upon my most recent lived experience. I must weigh the meaning of the other episodes that make up my past teaching activities: Remember how I managed to encourage that anxious but brilliant student to realize her potential? And there was the time that....

${ }^{4}$ While the search for the responsible actor begins with the disruption of a particular lived experience, it may not end there. Instead of blowing his horn in my presence, Shmoe may program his computer at Time ${ }_{1}$ to emit a blast just as I am studying my book at Time $_{2}$. In such cases, actions at earlier moments become relevant-but only so far as a theory of corrective justice can link them up appropriately to the moment of disruption. It is this latter time frame which continues to serve as the decisive reference point. For a classic treatment, see H.L.A. Hart and Tony Honore, Causation in the Law (New York: Oxford, 1985, 2nd ed.). 
Each element in this story may point to a particular lived experience; but the meaning and value I give to the activity point beyond particulars - to narratives that relate them into larger patterns of meaning. To put my point in a slogan: I live out my particular experiences but $I$ tell a story about my relationships. In the story I tell myself, I may be a good teacher despite bad classroom experiences from time to time, or vice versa. Indeed, words like 'good' and 'bad' hardly suggest the moral complexities involved in the ongoing effort to assess the implications of particular experiences for the stories we tell ourselves about our ongoing relationships.

Most importantly, the value of particular experiences is not exhausted by the role they play in our stories that seek to place them into larger temporal patterns. Even if I am convinced I am a good teacher, this does not somehow cancel out the badness of particular experiences. Similarly, I may make a mess out of a relationship and yet recall certain shining experiences. While the two temporal horizons are complexly intertwined with one another, their value cannot be reduced to one another. But if this is true of one's personal life, is it also true about justice?

I shall explore the matter by considering the ongoing revolution of our gender morality. Certain aspects may be readily expressed within the horizon of lived experience. For example, if we all took seriously the idea that our sexual partners had the right to say 'no' to our advances, this important step would not require the definition of a distinctive time horizon. It simply redefines the Shmoe-like behavior that should count as disruptive of another's expectations about the structure of particular lived experiences.

But other aspects of the gender revolution can only be understood against the more extended horizon of meaningful relationship. Consider, for example, the typical situation of a woman who wishes to gain professional recognition as a first-rate lawyer or professor or car mechanic. Suppose that the men in her environment are not disruptive in any of the familiar abusive ways-they do not hurl sexual insults or demand sexual favors, much less assault or rape. They may even respond to her with labored politeness. To make things hard for ourselves, suppose that when payday comes around, our hypothetical woman worker is highly compensated, in full recognition of her contributions to the institution's marginal revenue product. She has only one problem: her fellow workers do not take her seriously. But what precisely does this mean? 
Assume, for example, that a lady lawyer attends strategy session after strategy session in which the affairs of clients are discussed; on each occasion, she talks about as much as most participants, and nobody interrupts; but her contribution is never taken up by others in the subsequent give-and-take. Within the lived experience of each individual session, there is nothing odd about this fact. Everybody has been at meetings at which his or her contribution goes unnoticedeven if it aciually has a good deal of merit. The problem arises only when our not-so-hypothetical lawyer puts the episodés into narrative form; only then does the pattern emerge that is the object of her grievance. These guys just are not taking her seriously!

Despite her hefty paycheck, she is a victim of injustice. If you agree, we cannot express this judgment within the temporal horizon of corrective justice. We require a new idea-that justice requires us to respect each others' right to tell stories of a certain kind about our ongoing relationships.

Having taken this step, two paths open before us. One is consequentialist: if her fellow workers began to take her contributions seriously over time, perhaps the woman would rise to new professional heights, and (after a transition) perhaps the law firm would find itself better off in terms of profits and camaraderie.

But perhaps not. It is, alas, perfectly possible that once her colleagues began taking her seriously, they would find lots to criticize about aspects of her performance which they had formerly disdained to notice; or perhaps the woman, having gained the professional recognition she had long sought, concludes in despair that "success" in the activity was not worth the long years of sacrifice it required. Nonetheless, even if the woman only gains misery upon winning professional recognition, the men were doing her an injustice in withholding it. Here, as elsewhere, the utilitarian account fails to express the categorical character of judgments of injustice: the wrong done to the woman goes deeper than the fact-specific balancing of costs and benefits allows us to appreciate.

Rather than guess at probable outcomes, we should look to the way the work environment suppresses a fundamental human capacity-the capacity to project the meaning of one's life over time by telling a story that includes meaningful participation in relationships. Without such a capacity, it would simply be impossible to live a human life. A social environment that denies a woman this possibility strikes at a crucial dimension of human dignity-one that is no less fundamental than the horizon of lived experience protected by a concern with corrective justice. 
Just as corrective justice vindicates the very possibility of meaningful lived experience, so too relational justice vindicates the very possibility of meaningful participation in ongoing activities. If corrective justice requires each of us to act responsibly and avoid the wrongful disruption of lived experience, relational justice requires us to act responsibly by fairly recognizing the contributions others make to ongoing enterprises in which we participate. If we refuse to recognize this duty, we deny others their claim to dignity as fellow creatures in the search for a meaningful life.

Of course, a lot of questions must be resolved in the elaboration of this core idea: ${ }^{5}$ Does it embrace the organization of the family, religion, sport, as well as work? In what ways should respect for the contributions of others be manifested? When, if ever, may participants legitimately waive their right to something I will call a dignified relationship?

But let us complete the view of the forest before glancing at a few trees. A third horizon awaits.

\section{LIFE CHANCES}

Think of yourself writing your autobiography. Surely, you would reflect on particular lived experiences that were decisive. You would also organize these, and many other, experiences into narratives that define larger patterns of enduring relationship. But your life story could not be reduced to any single relationship, let alone a particular experience. An adequate autobiography would reveal the intricate interplay of experiences and relationships that express the complex meanings of your life as a whole.

Within this life-time framework, a different question of justice takes center stage. Like all mortals, you have struggled for meaning in a world you did not create. You did not choose your parents, or your education, or the material and transactional resources with which you began life as an adult. Yet these resources have transparently shaped the life story you tell in your more autobiographical moments. If you had begun life with different resources, you would have had different experiences, engaged in different relationships. Have you, then, been unjustly handicapped—or advantaged-from the start?

This is the question that motivates liberal theories of distributive justice and accounts for certain characteristic features that can otherwise easily be parodied. The first is their high level of abstraction. Since we are scrutinizing the distribution of basic resources out of which people build the meaning of their lives, the analysis will avoid

${ }^{5}$ This idea lies at the foundation of Catharine MacKinnon's argument in her Sexual Harrassment of Working Women (New Haven: Yale, 1979). 
the examination of particular lived experiences or relationshipssince, by liberal hypothesis, people should be free to organize them in the way they think best. Second, this temporal horizon also accounts for the theories' principled neutrality as to the nature of the good life: if basic resources are given out fairly, it is up to each of us to write our own autobiographies-for good or for ill. It is not for the liberal state to proclaim an authoritative answer to the mystery of life, and distribute resources on this basis.

I deny, however, that this abstract and antiteleological characterization justifies the familiar charge that liberal distributive theories presuppose an "unencumbered self," whose dignity can somehow be detached from life's experiences and relationships. On the contrary, it is precisely because human dignity can only be achieved through experience and relationships that distributive justice seems a matter of crucial importance. Since our particular experiences and relationships are profoundly shaped by our initial claims to basic resources, those claims had better be allocated in a justifiable way. In focusing on the distribution of initial endowments, liberal theories do not presuppose an unencumbered self; they simply suppose an autobiographical self, a self that can look back over the shape of her life and recognize that its starting point and subsequent development was profoundly shaped by political decisions allocating economic and cultural resources.

Indeed, thoughtful people who do take a radically "unencumbered" view of the self and its dignity-whether that view be based on Stoic or Christian or Buddhist or Kantian sources-have never been at the forefront of the struggle for social justice. For these people, a concern with such matters is part of the problem rather than part of the solution: since it is (they claim) an illusion that our successes and failures in the world of experience really matter for the salvation of our souls, it really does not matter how much or how little we have been given in terms of basic resources. The only important thing is to seek a spiritual state of radical detachment from the things of this world. Within this framework, a passionate commitment to distributive justice is merely a snare and delusion, leading one to place undue importance on worldly matters that are obstacles to salvation.

But this is hardly the spirit of modern liberalism. Whatever my differences with communitarians, they are not to be found in a dispute on the metaphysical relationship between the self and the world. Like any communitarian, I am happy to insist that selves gain value only through their encounter with experience and 
their reflection on their relationships. My disagreement arises only in response to a less metaphysical, but hardly unimportant, question: Who has the right to interpret the authoritative meaning that individuals give to their lived experiences and particular relationships?

For liberals, each person should be recognized as the authoritative author of her own autobiography. The fact that each person draws her life story from a particular community's legacy of language, practice, and tradition does not imply that she is any less the author of her own meanings in life. On the liberal view, the state oversteps its authority when it denies the legitimacy of this crucial act of self-definition.

In contrast, communitarians look with ironic distance upon each person's fragmentary and erratic efforts to construct a life story through ongoing processes of experience, relationship, and autobiographical reflection. Such Sisyphean labors should not blind us to the way individuals may casually destroy the legacy of collective meanings that make their puny efforts possible.

It follows that the communitarian has no principled objection to distributive decisions made in an avowed effort to preserve collective ideals of the good life that sustain the individual's search for meaning. For liberals, the state has overstepped its bounds when it distributes more basic resources to those who are expected to live out their lives in accordance with its scripted versions of meaning in life. Such state-sponsored teleologies offend basic liberal commitments as they are elaborated within the temporal frame each of us adopts at our autobiographical moments.

To put this point in parallel with my others: just as the horizon of lived experience frames a concern with corrective justice which emphasizes the centrality of the responsibility of persons, and the horizon of meaningful activity frames a concern with relational justice which emphasizes the dignity of persons, I shall say that the autobiographical horizon frames a concern with distributive justice which emphasizes the freedom of each person to interpret the meaning of her own destiny.

Even if this liberal framework for distributive justice were accepted, there are the usual difficulties in working it up into an incisive theory. Rawls has one way of proceeding. Nozick has another. I have my own opinions. But at least we are clearer why liberals find the question worth asking.

VI. CONFLICTING TEMPORALITIES

"Responsibility," "dignity," "freedom": I have introduced these three liberal ideals, and the way they emerge from three temporal hori- 
zons, one at a time. But when we put the horizons together, do they yield a consistent whole?

This question arises on at least two levels. The first implicates philosophical anthropology: Is there a consistent image of human life that organizes the three aspects of liberal justice as they are refracted by the temporal horizons?

A second involves the nuts-and-bolts construction of one or another theory of justice. As the theorist tries to understand the sources of a particular conflict, she is well advised to place it against the interpretive background provided by each of the three horizons. But each temporal framework may offer conflicting diagnoses of the just resolution of the dispute: ideals of responsibility may point in one direction, principles of dignity in another, notions of freedom in a third. When this happens, how to decide which temporal frame should be most salient?

Taking this second question first, I concentrate on the ways in which framing paradoxes, as I shall call them, would arise even in an ideal world-in which all inhabitants were willing and able to build a polity that perfectly complied with liberal principles. In adopting this counterfactual premise, I do not wish to divert attention from the deeply entrenched injustices of the real world. I adopt my idealizing posture only to suggest that even in the unlikely event that liberalism triumphed decisively in the world, it will still have things to worry about.

1. Reframing the meaning of lived experience. Imagine an ideal liberal world in which initial resources were justly distributed and where well-informed entrepreneurs and consumers operated in a competitive market economy. ${ }^{6}$ Considering your range of options, you have decided to open a McDonald's and devote your working life to customer service. Picture yourself happily flipping hamburgers when Shmoe enters and deliberately tries to destroy this experience and, with it, the means of your economic livelihood. Stipulate further that Shmoe is just plain nasty: though you have done him no wrong, he has no other mission in life but to make you miserable.

He succeeds: thanks to him, and him alone, your hamburger flipping comes to an end. This is the stuff of corrective justice-however much particular theories disagree on other matters, this looks like a paradigmatic case: Shmoe has done you wrong through intentional actions that have no other motive than sheer maliciousness. Until I add some further facts.

${ }^{6}$ I frame this characterization of the liberal market ideal abstractly to embrace a broad range of particular theories. 
Stipulate that Shmoe has not hired a goon squad to scare away your customers, but has opened up his own Hamburger Heaven next door out of pure spite. Driving down his prices, he drives you out of business, chortling loudly as the gas company shuts off your hot plate, ${ }^{7}$ and you leave the premises in despair. Do you still think he has done you wrong? Do you think that the liberal state should authorize you to sue him for compensatory (or punitive) damages?

These questions expose a tension between two horizons. From the vantage point of lived experience, the paradigmatic wrong is malicious and intentional disruption. Within the horizon of relationships, the episode has a different meaning - at least if you and Shmoe understand yourselves as engaged in the distinctive activity called entrepreneurship. Within this temporally-extended frame, we expect to be judged over time by how well we take advantage of opportunities opened up by the market-hence it is not wrong if you go under because somebody else has decided to undercut your price.

Even Shmoe's jubilation takes on a different appearance: Just as the baseball players who win the World Series jubilate on the field after their triumph, is there anything really wrong when Shmoe trumpets his own victories in the "game" of free competition? At worst, Shmoe has acted in bad taste, exhibiting emotions hidden beneath a veneer of polite concern by those with better breeding.

Is Shmoe, then, a loud boor or a monster of injustice? Perhaps this is not a problem that cannot be resolved cleanly one way or the other. I shall express this continuing sense of irresolution by saying that thoughtful partisans of one or another answer suspend rather than dismiss the objections raised by their opponents. Suppose, for example, that liberal citizens resolve the framing paradox by passing a law that allows Shmoe to escape from legal liability: "Whereas people should have the right to relate to one another as competing entrepreneurs in a market economy, they have the right to cut prices even when intentionally inflicting foreseeable harm upon other competitors...."

Most thoughtful advocates of this law will retain a capacity to experience the shock of injustice as they view the malignant Shmoe triumphing over his hapless victim. Thus, they will not find it possible to dismiss the proponents of corrective justice who find Shmoe's willful disruption morally wrong. Instead, they want to suspend this judgment as they focus on the way price cutting appears within a relational time frame: If entrepreneurs find it meaningful to relate to one another as participants in a

${ }^{7}$ Some might be impressed by the fact that it is the gas company, rather than Shmoe, that is the direct cause terminating your job. If you are one of them, stipulate that Shmoe owns the gas company. 
market economy, should the liberal state not respect their right to tell this story about themselves? If price cutting is a significant part of this story of competitive prowess, why should the state seek to ban it?

On the other hand, those who would pass a statute condemning Shmoe for "cut-throat competition" or "predatory pricing" will also be aware of a distinctive normative undertow. While they may insist that Shmoe is doing something wrong, they may find it difficult to blind themselves entirely to the stories entrepreneurs tell one another as they compete for business in the marketplace. In their view, however, these stories should not allow us to tolerate behavior that would otherwise be condemned within the frame of lived experience.

Although most of us tend to one of these suspensive views, I do not deny the existence of thoughtful people who are downright dismissive. Strong deontologists often suggest that intentional maliciousness can never be outbalanced by the beneficial consequences of activities. Unfortunately, they do not test the rigors of their doctrine by looking the Shmoes of capitalism in the face and telling us how they would run an economy that did not tolerate countless acts of intentional, short-run, harm doing. They write as if their critique of utilitarianism only had bite in crisis situations arising in war or other grave emergencies. ${ }^{8}$ Perhaps they can maintain the credibility of their rigorous doctrine only by blinding themselves to many of the cases that it would condemn?

This is, at least, the opinion of classical utilitarians, who have recently been reinforced by the American school of lawyer-economists. These analysts turn the tables on deontology by refusing to take seriously the frame of lived experience and by focusing all their attention on the extended frame of meaningful relationship. For them, the legitimacy of the marketplace serves as a paradigm for the analysis of other problems of conflict. If, as they suppose, the short-term cruelties of the marketplace are readily justified by a longer-term view of the benefits, a similarly expansive approach is appropriate when it comes to assessing other areas of social life.

From this perspective, it is naive to condemn a relationship merely because it looks morally unattractive at a particular point in time. Almost every activity worth doing has its unattractive moments. The question is whether these bad patches are outweighed by the good ones that the activity generates at other times. If the answer is 'yes',

${ }^{8}$ See, for example, Judith Jarvis Thomson on trolleys, in The Realm of Rights (Cambridge: Harvard, 1990), chap. 7; Bernard Williams on wartime atrocities, in "A Critique of Utilitarianism," in J.J.C. Smart and Williams, Utilitarianism: For and Against (New York: Cambridge, 1973), pp. 98-100. 
the right thing to do is to transcend the primitive moralisms of lived experience and embrace the activity with all its imperfections-so long, at least, as you have taken steps to minimize the bad and maximize the good it generates over time. By the simple act of transvaluing time horizons, we have shifted decisively away from deontology toward maximizing cost-benefit analysis.

But is it really necessary for us to continue dismissing one another in these familiar ways? On the one hand, the utilitarian is surely right in pointing out the naiveté of fixating on bad moments without giving credit to the good an activity can produce. On the other hand, the deontologist is right to point to the special terror we feel when some rival intentionally disrupts our lived experiences without even attempting to justify his actions by appealing to principles of corrective justice.

Rather than dismiss either of these points, liberal public policy should aim to express the moral insights expressed on both sides of the framing paradox. For example, we should allow entrepreneurs to drive their competitors out of business, but require them to pay a special tax to cushion the unemployment that their intentional behavior predictably causes.

I suspect that similar straddles are also available in other areas of social policy.

2. Reframing the question of dignity. A different kind of straddling is in order when confronting a second framing paradox. This one arises when we juxtapose the relational horizon against the life-story perspective we adopt in our autobiographical moments.

I introduce the paradox as it might appear from the vantage of ideal theory. To fix ideas, suppose that each citizen of our ideal state receives a liberal education introducing her to a broad range of life options, that each begins adult life with a roughly equal share of wealth, ${ }^{9}$ and that each is held responsible for disruptive behavior by a system of criminal and civil law rooted in a sound understanding of corrective justice.

Citizen Freedom emerges from her period of tutelage to consider the job choices that are offered up to her in a competitive marketplace. After surveying her full range of choices, Freedom narrows her options down to two: a dignified workplace in which her fellow workers treat her contributions with the respect they deserve and

${ }^{9}$ I try to justify these, and other basic entitlements, in my Social Justice in the Liberal State (New Haven: Yale, 1980). Other liberal theories understand distributive justice differently, but in many cases, these differences will not change the basic structure of the framing paradox of interest here. 
which pays a salary of $\$ 35,000$ a year; an undignified competitor, in which the little ladies are treated in a polite, but unserious, manner by their male colleagues-even though they are paid $\$ 40,000$ !

This is not as impossible as it may sound. To use economic jargon, all it requires is that some men gain enough "psychic income" from machismo that they are willing to sacrifice enough dollars so as to offer Citizen Freedom a deal on undignified terms. ${ }^{10}$ Stipulate further that Freedom acts under conditions of perfect information-she is carefully told what the terms of the deal involve. After weighing the matter, Freedom accepts the offer of undignified employment-taking the bigger paycheck and salving her ego with a fancy mink coat.

Unless, of course, the citizenry intervenes to make this kind of transaction illegal. If the woman had not consented, liberal principles would indeed condemn organizations that stripped her of her dignity. Does the bare fact of her consent make such a big difference?

My own answer emphasizes the distinction between ideal theory and real-world conditions. When considering the question as it would arise in an ideal liberal state, you should not assume that Citizen Freedom has received an illiberal education which sought to indoctrinate her in a life of feminine subordination; nor should you assume that Freedom comes from the lower classes and chooses the higher income because she has been unfairly deprived of a roughly equal starting point in life. These real-world factors do give rise to a very powerful argument in favor of banning dignity-stripping arrangements, even those reached by knowledgeable adults in uncoerced settings. Quite simply, given the existing injustices in the distribution of educational and material resources, do we want to allow Citizen Freedom to reinforce by her conduct the idea that there is nothing wrong with stripping women of their dignity?

But such questions are excluded by definition in my idealizing thought experiment, which challenges us to consider whether, even in an ideal world, Freedom should be barred from stripping herself of her own dignity as a worker by trading it for cash. I answer by affirming the value of freedom over dignity: when push comes to shove, I place the highest value on the freedom of each citizen to organize activities and experiences into a life story that she finds meaningful. If Citizen Freedom knowingly sacrifices her dignity on the job

${ }^{10}$ This theme is elegantly explored (without too many moralizing words like 'dignity') by Robert Frank in Choosing the Right Pond (New York: Oxford, 1985). 
to gain resources for the more meaningful pursuit of other activities, it is not for the state to say that she is wrong.

Of course, one should make very sure that there is a real conflict between freedom and dignity before allowing the latter to be sacrificed. Consider prostitution-a paradigmatically undignified activity as it is generally practiced. Doubtless, many prostitutes are driven to the activity by unjust conditions of poverty and inadequate education. Others do not know what they are in for. While all this justifies a great deal of regulation, I do not think it justifies an outright ban. If a twenty-year old with a good education decides to make money off her body by selling it to partners (who do not physically abuse her), she should be treated as the ultimate author-ity in the matter. Even in the real world, legitimate concerns for dignity should never eliminate the possibility of freedom.

But let us return to ideal theory, and probe more deeply into the framing paradox. Suppose now that Citizen Freedom goes further, and announces her intention to enslave herself totally and forever to a master. Must the liberal state allow her to strip her claims to dignity so completely?

Many of my friends respond by refusing to answer. After all, they point out, we are dealing in ideal theory, and therefore should suppose that Freedom has begun life with her fair share of basic resources. Under such conditions, it is almost impossible to suppose that she will "voluntarily" choose slavery.

I agree that it is unlikely, but it is always a mistake to underestimate human freedom, and its variety of uses. Ideal theory is ideal in its grant of equal freedom to all; it does not guarantee that citizens make an ideal use of their freedom. Let us stipulate, then, that one of our fellow citizens announces her intentions to become a slavefor-life-if only to expose the shallowness of liberal ideals. Does she have this right to strip away her dignity?

Begin by distinguishing this extreme case from the others we have considered-on two dimensions. First, most dignity-stripping cases allow the stripper to change her mind after a relatively short period of time. Recall my earlier hypothetical case involving a woman worker trading $\$ 5,000$ in salary for undignified treatment. If she tires of this deal, she remains free to change her life story by changing to a job that promises lower pay for more dignity. Second, most other cases involve piecemeal stripping of dignity in one activity, leaving the citizen free to write a dignified autobiography by emphasizing her other activities and experiences. 
In contrast, the slavery-for-life case involves a person who is completely stripping herself of her author-ity. She is denying that she is the sort of creature who takes responsibility for writing an autobiography. ${ }^{11}$

I would draw the line at this point, and refuse to recognize the legitimacy of the action. Of course, if somebody were grimly determined to disclaim all author-ity, there may be precious little we can do in practice to stop her-other than to make it clear that we would prevent the master from maintaining his dominion if she should ever express the desire to take up her life again as a free citizen of the liberal state.

In any event, my aim here has not been to resolve such paradoxes, but to urge you to consider them with greater care. VII. METAPHYSICAL FOUNDATIONS OF LIBERALISM

In a recent essay, ${ }^{12}$ I reaffirmed my faith in political liberalism-so long as one did not take its promises of liberation from metaphysics and epistemology too seriously. While political liberals try, as a matter of principle, to evade contestable matters of first philosophy, they do not suppose they can altogether avoid such confrontations.

This essay has pointed to one of these necessary encounters. No serious theory of justice can evade the ancient dispute between monists and dualists. It arises whenever the debate becomes self-reflexive and considers the basic structure of the idea of justice itself. While monists have the advantage of Ockham's Razor-Why make a difficult subject more complicated than necessary?-dualists succeed in raising nagging doubts about the adequacy of any monistic conception to do justice to our considered convictions.

Rather than repeat pat dualistic formulae, I have tried to reflect upon fundamental aspects of the human condition and show how they may motivate a trinitarian response. Since the problem of justice only arises amongst creatures endowed with time consciousness, I have searched for an answer by elaborating a more general account of the struggle for meaning in time, seeking to show how it might enlighten our particular problem.

I have tried to conduct this search in the spirit of political liberalism-providing just enough metaphysics to motivate a thoughtful answer without indulging elaborate metaphysical conceits that needlessly alienate people who might otherwise embrace liberalism's

"Compare Harry Frankfurt's treatment of the wanton in his "Freedom of the Will and the Concept of a Person," this Journal, LXVII, 1 (January 14, 1971): 1014.

12 "Political Liberalisms," this JOURNAL, XCI, 7 (July 1994): 364-86. 
key commitments. Despite the wild diversity of outlooks held by the citizens of a modern society, are there really lots of people out there who fail to recognize the relevance of the three temporal horizonslived experience, meaningful relationship, life story-which frame their search for meaning in life? I do not think so.

If my thesis is novel, it lies in the effort to link this spare metaphysic to the problem at hand. In making this link, I do not claim that the three temporal horizons are themselves sufficient to solve the trinitarian problem of justice they reveal. Merely because all of us struggle for meaningful experiences/relationships/lives, it does not follow that we all adopt the same principles of justice when our struggles for meaningful experiences/relationships/lives conflict with one another.

As we reflect on the framing paradoxes that ensue, liberals may find it necessary to probe more deeply into the metaphysical foundations of the self's encounter with time. In my brief introduction to framing paradoxes, I have suggested my own strong priority to the self's struggle for a meaningful autobiography over the claims of particular relationships and lived experiences. But I shall leave a more extended defense of this priority to another time.

BRUCE ACKERMAN

Yale University 